\title{
Effect of stagger on the vibroacoustic loads from clustered rockets.
}

\author{
Raymundo Rojo* \\ Center for Aeromechanics Research, The University of Texas at Austin, Austin, TX 78712, USA \\ Charles E. Tinney ${ }^{\dagger}$ \\ Applied Research Laboratories, The University of Texas at Austin, Austin, TX 78713, USA \\ Joseph H. Ruf ${ }^{\ddagger}$ \\ NASA Marshall Space Flight Center, Huntsville, Alabama 35812, USA
}

\begin{abstract}
The effect of stagger startup on the vibro-acoustic loads that form during the endeffects-regime of clustered rockets is studied using both full-scale (hot-gas) and laboratory scale (cold gas) data. Both configurations comprise three nozzles with thrust optimized parabolic contours that undergo free shock separated flow and restricted shock separated flow as well as an end-effects regime prior to flowing full. Acoustic pressure waveforms recorded at the base of the nozzle clusters are analyzed using various statistical metrics as well as time-frequency analysis. The findings reveal a significant reduction in endeffects-regime loads when engine ignition is staggered. However, regardless of stagger, both the skewness and kurtosis of the acoustic pressure time derivative elevate to the same levels during the end-effects-regime event thereby demonstrating the intermittence and impulsiveness of the acoustic waveforms that form during engine startup.
\end{abstract}

\section{Nomenclature}

A Area, $\mathrm{m}^{2}$

$D$ Diameter, $\mathrm{m}$

E Energy density of the wavelet transform, $\left[\right.$ units $\left.^{2} / \mathrm{Hz}\right]$

$f$ Frequency, $\mathrm{Hz}$

$f_{s}$ Sampling frequency, $\mathrm{Hz}$

$\delta f$ Frequency resolution, $\mathrm{Hz}$

$K$ Kurtosis

$l$ Wavelet scale

$N$ Number of samples, \#

$p$ Pressure signal, $\mathrm{Pa}$

$\tilde{p}$ Complex valued wavelet coefficient,

$\psi$ Mother wavelet

$r^{*}$ Nozzle throat radius, $\mathrm{m}$

$S$ Skewness

$t$ Time, s

$\sigma_{p}$ Standard deviation of $\vartheta(t)$,

$\dot{\vartheta}$ Time derivative of $\vartheta(t)$, [unit]/s

$\omega_{\psi}$ Central frequency of the mother wavelet, $\mathrm{Hz}$

$x$ Axial coordinate, y Normal coordinate,

$j$ (subscript) Nozzle exit plane static condition

$\infty$ (subscript) Ambient condition

0 (subscript) Stagnation condition

$f$ (subscript) Full-scale

* (superscript) Nozzle throat condition

EER (acronym) End-effects-regime

FSS (acronym) Free shock separated flow

GWPS (acronym) Global wavelet power spectra

NESC (acronym) NASA Engineering Safety Center

NI (acronym) National Instruments

NPR (acronym) Nozzle pressure ratio

OASPL (acronym) Overall sound pressure level, dB

PDF (acronym) Probability density function

RSS (acronym) Restricted shock separated flow

SPL (acronym) Sound pressure level, dB

TOP (acronym) Thrust optimized parabolic

WPS (acronym) Wavelet power spectra

${ }^{*}$ Graduate Research Assistant, AIAA Student Member.

${ }^{\dagger}$ Research Associate, AIAA Associate Fellow. http://www.ae.utexas.edu/facultysites/tinney/

$\ddagger$ Aerospace Engineer, ER42/Fluid Dynamics Branch, AIAA Member. 


\section{Introduction}

Many modern day space launch vehicles utilize high area ratio rocket nozzles with Thrust Optimized Parabolic (TOP) contours. This design is chosen due to its excellent thrust to weight ratio at vacuum. ${ }^{1}$ During startup however, the internal flow within the nozzle progresses through a series of flow and shock wave patterns that produce both lateral and vibroacoustic loads on the vehicle and surrounding structure. ${ }^{2}$ A quantitative assessment of these loads is a necessary step to ensuring that the vehicle and its occupants are safe. Here we seek to add new insight to this problem by characterizing the effect engine stagger has on these vibroacoustic loads during the startup of a clustered rocket configuration comprising TOP nozzles.

For TOP contoured nozzles that experience both free-shock separated (FSS) and restricted-shock separated (RSS) flow, ${ }^{3,4}$ the nozzle pressure ratio (NPR, the ratio of plenum pressure $P_{0}$ to atmospheric pressure $\left.P_{\infty}\right)$, is the key determinant of the flow state. At a low pressure ratio the flow will be in a FSS flow state. At moderate pressure ratios, the internal flow undergoes FSS $\rightarrow$ RSS transition. ${ }^{5}$ The flow remains in RSS as the NPR increases some amount, up to the NPR at which the flow transitions to an FSS-like flow state identified as the end-effects regime (EER). ${ }^{6}$ The flow, for some TOP nozzle contours, then enters a periodic pulsation where the flow transitions rapidly back and forth between RSS and EER that has been called end-effect. ${ }^{7}$ These end-effect pulsations have been identified as a significant source of nozzle side loads. ${ }^{7,8}$ Beyond the end-effect, as NPR increases further, the nozzle flows full. Of particular interest to this study are the end-effect pulsations, i.e., the nozzle flow's oscillation between RSS and ERR and the acoustic load that it generates. The magnitude of the acoustic loads during rocket engine start transients has garnered significance interest as they pose a risk to nearby components of the launch vehicle.

Methods for mitigating these loads is exacerbated by the complexity of the hardware and launch sequence, as well as the preference towards selecting heritage hardware with a proven track record of performance. Thus, any changes to the number and orientation of the rocket engines requires testing to ensure that the vehicle is capable of withstanding these loads. While laboratory testing, using geometrically scaled replicas of the full-scale system, can be conducted at a fraction of the cost of the actual full-scale testing, the process for measuring these vibroacoustic loads is not entirely straightforward and is dependent on a great many factors that are difficult to replicate accurately in a laboratory environment.

Foremost, the full-scale environment is much more elaborate and manifests additional factors that are often not accounted for in a laboratory scale setting. That is, the full-scale environment includes acoustically reflective surfaces caused by the presence of the launch pad and tower, a sound suppression system formed by water, as well as additional complexities that form from having compliant walled nozzles that bend and flex during operation. ${ }^{9}$ A flame trench also redirects the rocket exhaust flow, which changes the apparent location of the prominent source of sound relative to the launch vehicle. Variations in nozzle stiffness and the stress or deformations induced in previous firings of the engine are also difficult to account for. These can influence the FSS $\rightarrow$ RSS transition resulting in different acoustic load levels, which may even amplify or cancel one another in the case of clustered nozzles.

Several decades now of research on rocket noise have resulted in a general understanding of the acoustic footprint produced during launch and ascent of liquid and solid propellant vehicles. ${ }^{10-18}$ In this study, the motivation is to better understand both the statistical and spectral characteristics of the acoustic waveforms that act on the vehicle aft end during the end-effects regime. This study is part of a larger effort between The University of Texas at Austin and the NESC to obtain experimental databases with which a refined estimate can be developed for the EERs acoustic load magnitudes and spacial variation on the aft end of a future launch vehicle. We begin by analyzing data corresponding to several full-scale launch missions in order to reveal the sensitivity of the acoustic waveform shapes to the startup sequence. The launch sequence is then repeated using a geometrical scaled replica of the full-scale system (including rocket nozzles and vehicle geometry) with a focus on the end-effects regime. The same analysis tools are exercised on laboratory data in order to identify parallels between the laboratory and full-scale environments. Particular attention to the effect that engine stagger has on these various statistical metrics is explored.

\section{Full-Scale Study}

We begin by analyzing the dynamic pressure acting on the base of a full-scale launch vehicle comprising three large area-ratio liquid propellant engines. The data is acquired during several engine ignitions and is measured using an acoustic microphone embedded in the base of the vehicle (behind the nozzles) and 
digitized at $f_{s}=10 \mathrm{kHz}$; an image of the full-scale rocket system is shown in Fig. 1. Nozzle pressure ratios are shown in Fig. 2a and demonstrate both the consistency between engines and the variation of NPR during engine startup. A staggering effect is employed and is revealed in Fig. $2 \mathrm{~b}$ where $\Delta \mathrm{NPR}_{i, j}$ is the difference in nozzle pressure ratio between the $i^{t h}$ and $j^{t h}$ engines. This staggering effect exhibits nearly linear growth between NPR 88 and 128 which is when the engines experience the end-effects-regime (EER). Evidence of EER is shown in Fig. 3a using an arbitrarily scaled sample of the microphone data. The ordinate axis labels for Fig. 2 and Fig. 3 comprise the NPR of the first engine.

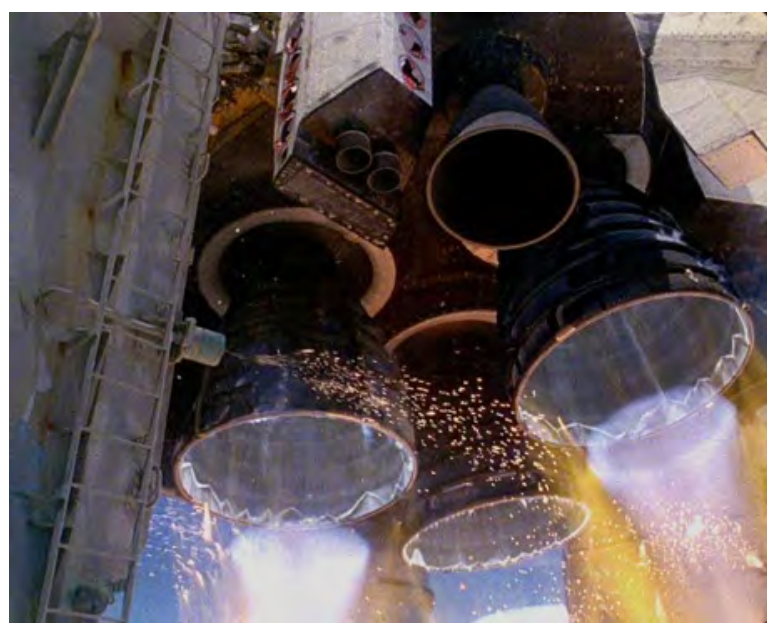

Figure 1: Image of three full-scale liquid propellant engines undergoing staggered startup (Courtesy: NASA).

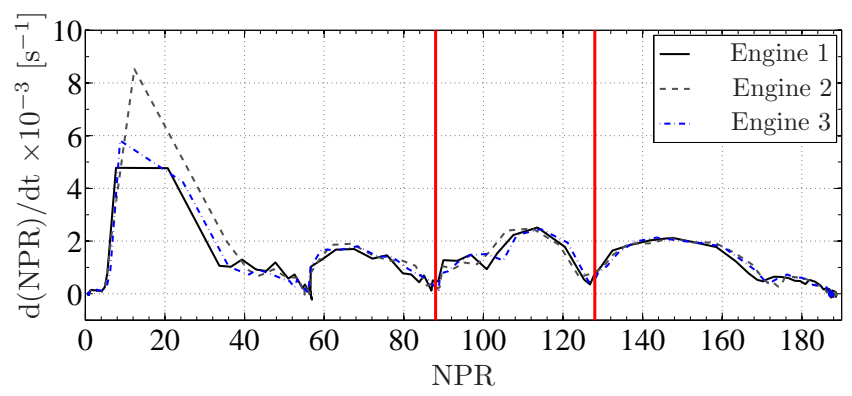

(a)

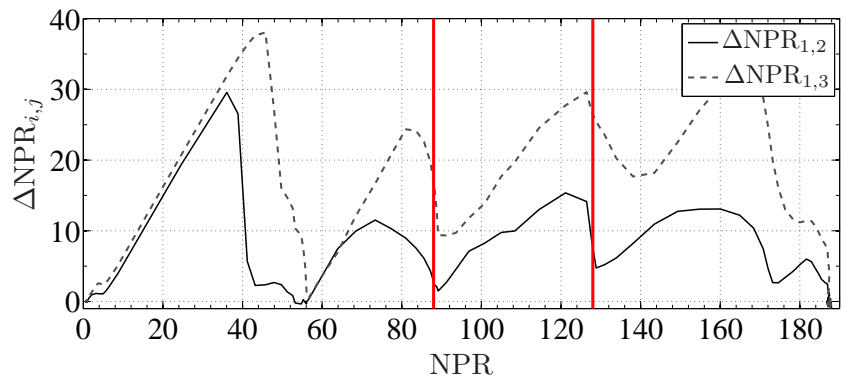

(b)

Figure 2: (a) Nozzle pressure ratios during staggered startup of three full-scale liquid propellant rocket engines. (b) Difference in Nozzle Pressure Ratio between the $i^{t h}$ and $j^{\text {th }}$ engines during startup.

Three unique peaks are revealed (labeled 1,2, and 3), which correspond to the instant in time when each of the three engines undergo the end-effects regime. Dark lines bound the maximum and minimum pressure amplitudes that form within this envelop of time with fourteen launches of similar NPR time-histories being superposed in Fig. 3b. Vertical lines identify the range of NPR in which the pressure variation is most 
energetic, which is shown in Fig. 3b to occur repeatedly between NPR 88 and 128 for all launches. In order to understand the spectral and statistical make up of the pressure waveforms that form at the base of the vehicle during liquid engine startup, the time series in Fig. 3 are scrutinized using both standard metrics (second, third and forth central moments) as well as a time-frequency analysis.

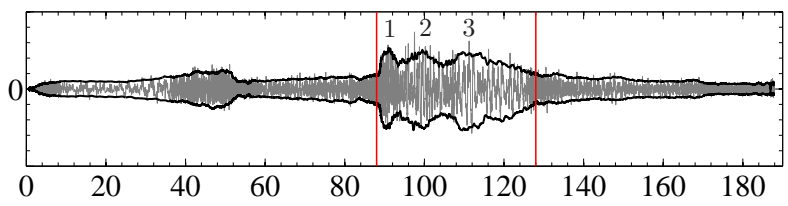

(a)

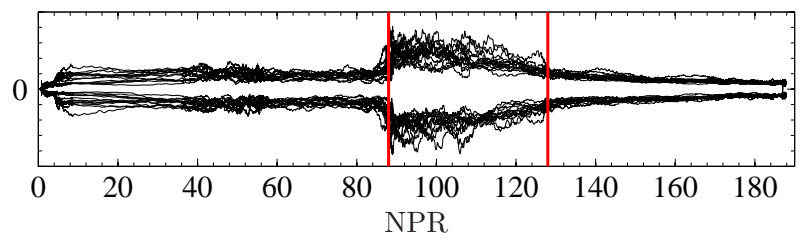

(b)

Figure 3: (a) Acoustic pressure data acquired during staggered startup of three full-scale engines. (b) Overlap of maximum and minimum envelops for 14 launches. Vertical lines bound the NPR range in which the end-effects regime occurs.

Starting with the scalar metrics, all fourteen full-scale pressure signals are examined by window averaging the data using overlapping bins of 500 samples per bin (50ms) with each bin shifted by 100 data points. Small deviations to the bin size appeared to have a negligible effect on the results. The findings are shown in Fig. 4, and reveal the OASPL (referenced to $20 \mu \mathrm{Pa}$ ) as well as skewness, $S(\vartheta)=\bar{\vartheta}^{3} / \sigma^{3}$, and kurtosis, $K(\vartheta)=\bar{\vartheta}_{-}^{4} / \sigma^{4}$, of the acoustic pressure and its time derivative. Here, $\sigma$ is the standard deviation of $\vartheta(t)$, and $\bar{\vartheta}^{3}$ and $\bar{\vartheta}^{4}$ are the third and fourth central moments of the probability density function (PDF), respectfully. ${ }^{19}$ The time derivative is obtained using a first order finite difference scheme. For each metric shown, the average (over all fourteen launches illustrated in Fig. 3b) is superposed with the result from the single time series shown in Fig. 3a.

Where the OASPL is concerned, Fig. 4a illustrates a dramatic drop in the acoustic pressure around NPR 50 , followed by a rapid rise around NPR 90 that gradually fades with increasing NPR. The drop at NPR 50 is attributed to the advancing of the internal flow from a circular supersonic flow to an annular supersonic flow surrounding an open-ended subsonic core. A discussion of this is provided by Donald et al. ${ }^{10}$ and results in a relatively higher acoustic impedance that is most noticeable at shallow angle to the rocket plume. Above NPR 90, the trend is as expected, given the time-series envelope displayed in Fig. 3b. For the single launch, three distinct peaks are revealed which coincide with the three end-effects regime events in Fig. 3a. Not all pressure waveforms revealed these distinct peaks as evidenced by the scatter in Fig. $3 \mathrm{~b}$ and the relatively flat profile from the average OASPL. The cause of the different EER induced acoustic levels has not been determined. The differences could be caused by variations in nozzle initial shape and nozzle stiffness, nozzle wall temperature, gas constituents ${ }^{9}$ and possible additional combustion in the recirculating flows.

As for the higher order statistical metrics, these are a necessary utility for characterizing the impulsiveness and intermittency of the pressure waveforms that form during the startup sequence. ${ }^{20}$ In particular, the skewness of the pressure time derivative is a useful indicator of waveform steepening, either by cumulative nonlinear distortion or through coalescence from neighboring waveforms. Steepened waveforms comprise rapid compressions followed by gradual expansions and are significantly more violent than waveforms composed of one or two simple harmonics. Likewise, kurtosis values that deviate from a value of 3 indicate the presence of intermittent activities in the waveform. Glancing at Fig. $4 \mathrm{~b}$ and $4 \mathrm{c}$, the trends are difficult to decipher. The average quantities suggest that pressure waveforms generated by EER pulsations are only weakly distorted, whereas the single time series has a significant distortion around NPR 110. The kurtosis factor in Fig. 4d and 4e manifests similar discrepancies. For instance, the kurtosis of the raw signal (as oppose to the time derivative of the signal) is greatest during the end effects regime, but appears insignificant when 


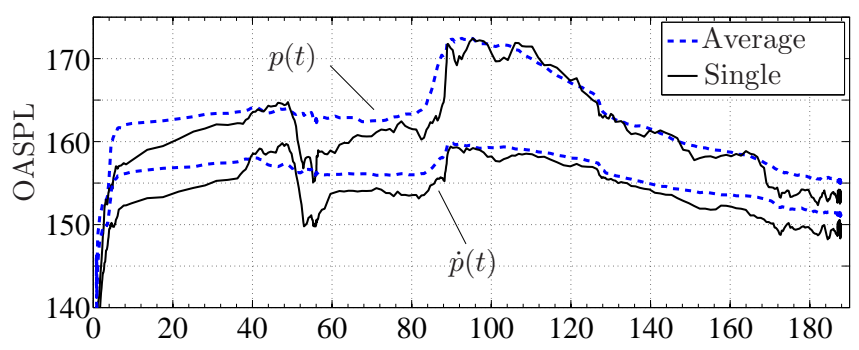

(a)

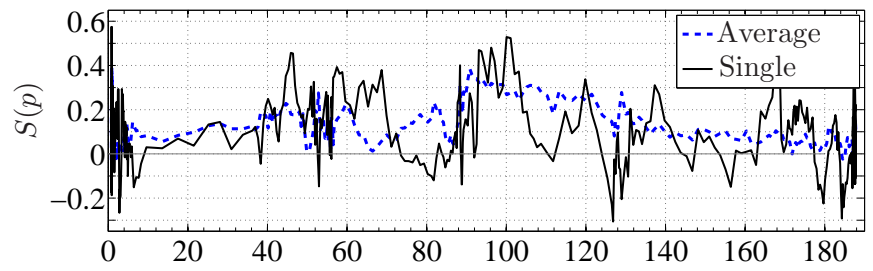

(b)

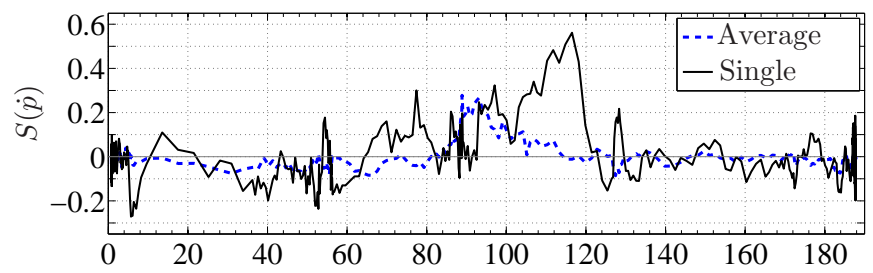

(c)

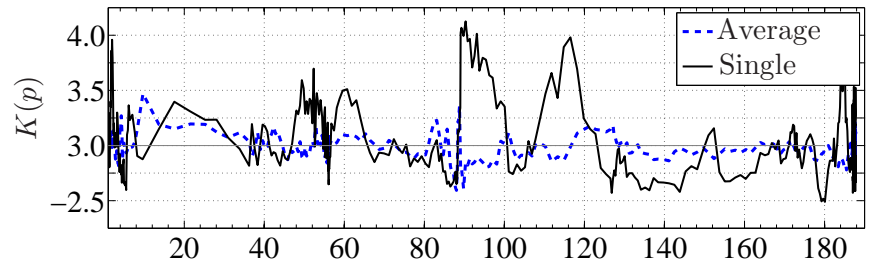

(d)

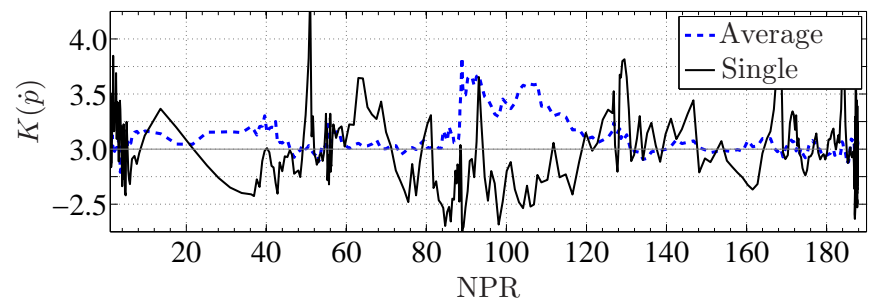

(e)

Figure 4: Window averaged (a) OASPL ( $\mathrm{dB}$, re: $20 \mu \mathrm{Pa} \sqrt{\mathrm{Hz}}$ ) of the pressure signal $p(t)$ and its time derivative $\dot{p}(t)$, skewness of the (b) pressure signal and (c) its time derivative and kurtosis of the (d) pressure signal and (e) its time derivative.

averaged over all fourteen launches. Overall, the findings reveal the presence of intermittent and impulsive 
like waveforms acting on the base of the vehicle during EER, with the discrepancies being a testament to the sensitivity of the averaging process when considering full-scale engine data.

In order to gauge the spectral content associated with these waveforms, wavelet power spectra are computed, which are resourceful methods for quantifying the frequency content associate with transient unsteady signals. ${ }^{21-23}$ In short, the transform convolves a mother wavelet $\psi(t / l)$ with an arbitrary waveform $p(t)$ in order to produce wavelet coefficients. Here, the Morlet wavelet is selected and is defined as $\psi(t / l)=e^{j \omega_{\psi} t / l} e^{-|t / l|^{2} / 2}$ with a central frequency of $\omega_{\psi}=6$. The transform is performed in the Fourier domain using 81 different scales $(l)$ distributed logarithmically across the frequency range $10 \mathrm{~Hz}<f<f_{f} / 2$. Only the regions inside the cone of influence are shown. The energy density is thus determined by,

$$
E(l, t)=\frac{|\tilde{p}(l, t)|^{2}}{l},
$$

and is obtained using complex-valued wavelet coefficients $\tilde{p}(l, t)$ defined as,

$$
\tilde{p}(l, t)=\int p\left(t^{\prime}\right) \bar{\psi}\left(\frac{t^{\prime}-t}{l}\right) d t .
$$

In Fig. 5a the WPS of a single launch reveals a pronounced high amplitude hump between NPR 88 and NPR 128 and centered on $140 \mathrm{~Hz}$. Upon averaging the WPS over all fourteen available launches, the resultant spectra is shown in Fig. 5b and appears unaffected by the averaging process. This demonstrates how a single launch provides sufficient detail concerning the spectral make up of the acoustic pressure that forms during the startup of these large area ratio nozzles. As for the spectral content leading up to, and after the event,

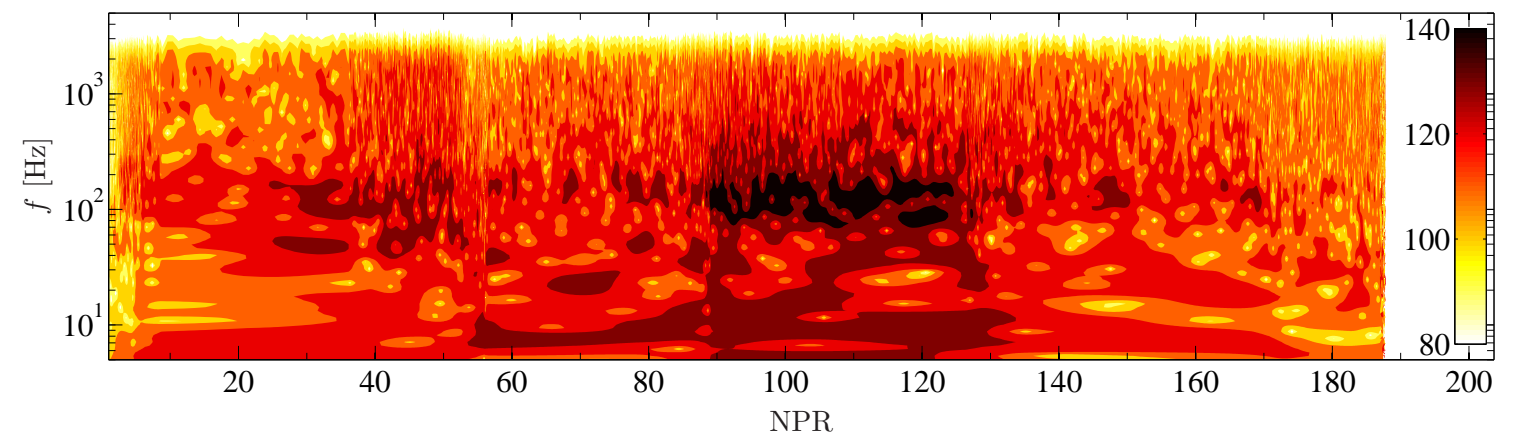

(a)

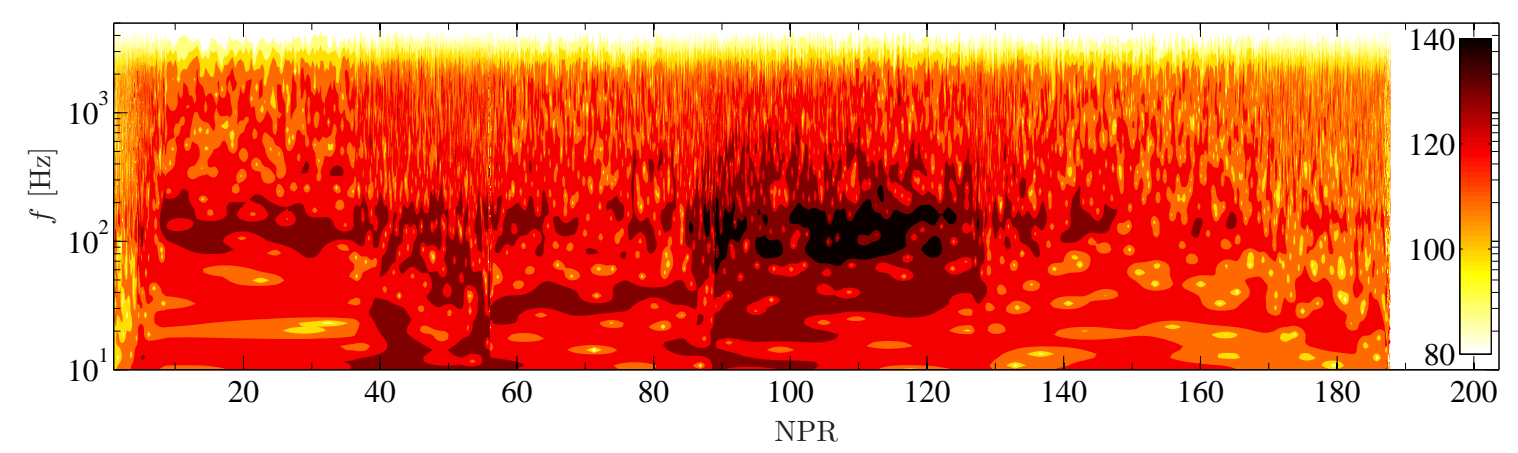

(b)

Figure 5: Morlet wavelet power spectra for the startup of the full-scale engines plotted in [dB], (ref: $20 \mu \mathrm{Pa} / \sqrt{\mathrm{Hz}})$, following $10 \log _{10}(E(f, t) /$ ref $)$. (a) WPS of one launch. (b) WPS averaged over fourteen launches.

this is shown to be relatively broadband with no significant tones or humps. Given the relatively small changes in the wavelet power spectra during the end effects regime window, a global wavelet power spectra (GWPS) is generated by averaging the wavelet power spectra between NPR 88 and 128 . The findings are shown in Fig. 6 alongside a Fourier analysis of the same time series window and display a clear spectral peak at $140 \mathrm{~Hz}$, followed by a second, lower amplitude peak at $85 \mathrm{~Hz}$. 


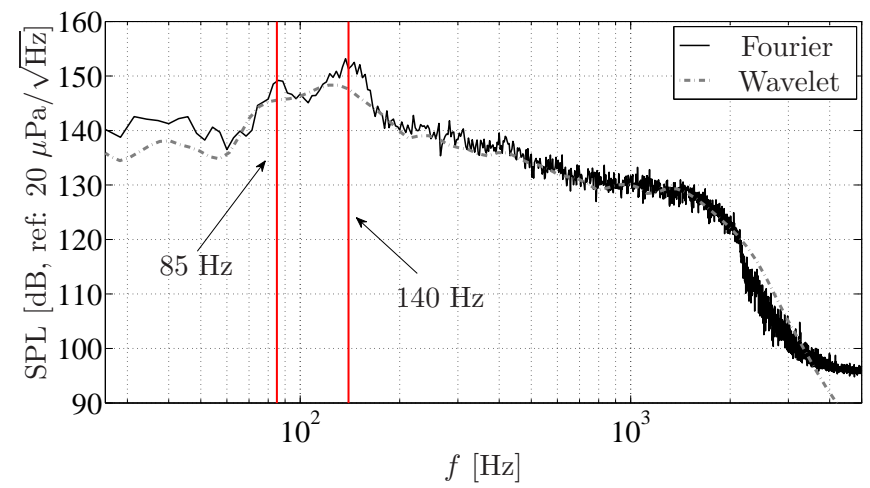

Figure 6: Global wavelet power spectra generated by averaging the wavelet power spectra in Fig. 5b between NPR 88 and NPR 128.

\section{Laboratory Scale Study}

\section{A. Facility and Instrumentation}

In order to understand the effect of engine stagger on the pressure waveforms that form during the startup transient, a laboratory scale replica of the full-scale system including vehicle geometry was constructed and tested in the fully anechoic chamber and open jet wind tunnel at The Applied Research Laboratories at The University of Texas at Austin. A description of the facility is provided by Baars and Tinney ${ }^{23}$ and Donald et al., ${ }^{10}$ and allows reduced- scale rocket nozzles to be tested in an acoustically treated environment and in the absence of an ejector diffuser. A nozzle test stand with a cluster of three rocket nozzles (Fig. 7) is installed at the center of the anechoic chamber and along the centerline of the wind tunnel. All three nozzles

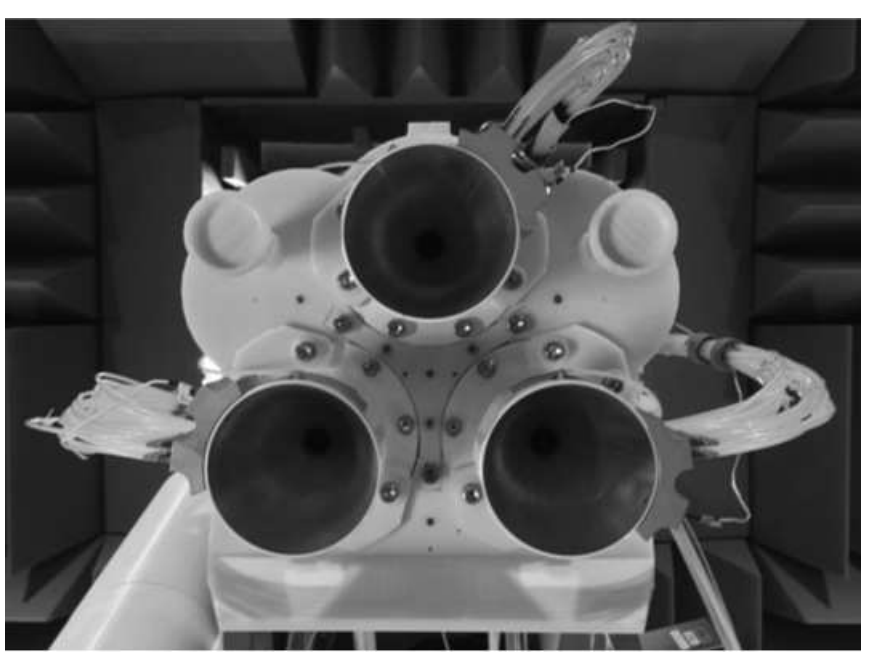

(a)

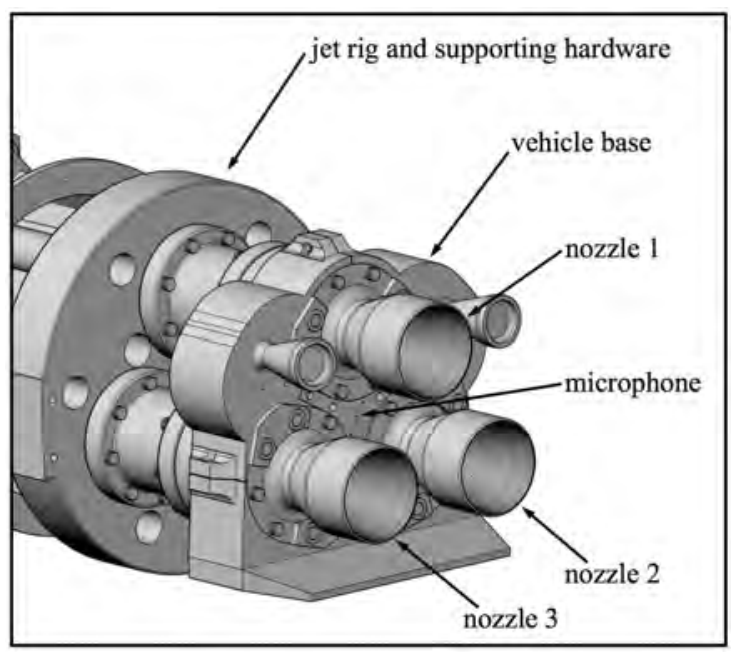

(b)

Figure 7: (a) Image of laboratory scale rocket cluster and vehicle base installed on the jet rig at The University of Texas at Austin. (b) Computer aided design model of clustered rocket identifying microphone location.

are connected to a manifold that allows unheated compressed gas (air in this case) to flow from a single pipe with control valve to the nozzle cluster. The nozzle contours are thrust optimized parabolic (TOP) and are designed to ensure both FSS and RSS flow during startup. For a single nozzle, FSS $\rightarrow$ RSS transition occurs around NPR 24. The three nozzle axes are parallel to one another and are oriented to form an equilateral triangle, as shown in Fig. 7, with a vertex height of 1.400 nozzle diameters. An illustration of the nozzle 
contour is shown in Fig. 8a and comprises a throat radius of $r^{*}=6.35 \mathrm{~mm}(0.250 \mathrm{in})$, an exit diameter of $D_{j}=69.89 \mathrm{~mm}(2.752 \mathrm{in})$ and an exit-to-throat area ratio of $A_{j} / A^{*}=30.29$. The design Mach number is 5.24 and would be achieved with a nozzle pressure ratio of approximately 700 . Full flowing conditions are achieved at a NPR of approximately 80 (overexpanded); see Ruf et al. ${ }^{24}$ for an overview of the nozzle contour used in this study.

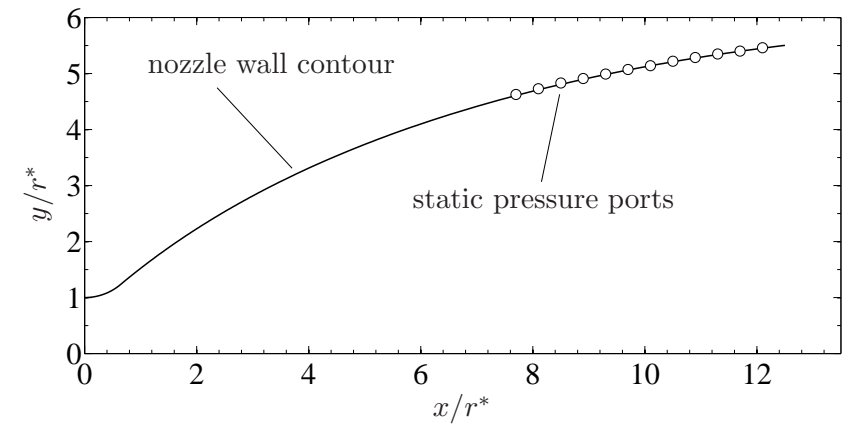

(a)

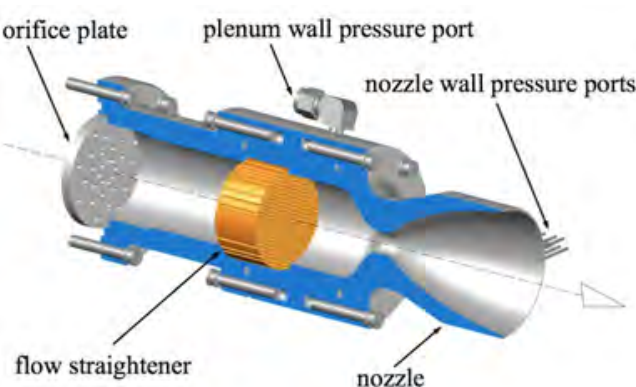

(b)

Figure 8: (a) Laboratory scale nozzle contour with static (Scanivalve) and dynamic (Kulite) wall pressure ports indicated. (b) Cutaway of plenum and rocket nozzle.

Nozzle stagger was achieved by inserting orifice plates in the nozzle plenum upstream of the nozzle throat and flow straightener, as shown in Fig. 8b. These orifice plates work by increasing the pressure loss through the piping system of one nozzle relative to the other. The orifice plates were installed upstream of the plenum and flow straightener as shown in Fig. 8b. Nozzle stagger was accomplished by decreasing the number of open holes (by different amounts) in the orifice plates. The nozzle numbering system is chosen such that the first nozzle is located at the top of the cluster with additional nozzles being counted in the clockwise direction as seen in Fig. 7. For stagger startups, the NPR curve is shown in Fig. 9 using the pressure ratio of the first nozzle to define the ordinate axis. Plenum pressures were sensed downstream of the flow straightener and before the subsonic contraction, as shown in Fig. 8b, where the Mach number (for all NPRs) is estimated to be 0.036 . Plenum pressures are recorded independently for each nozzle using three dedicated transducers

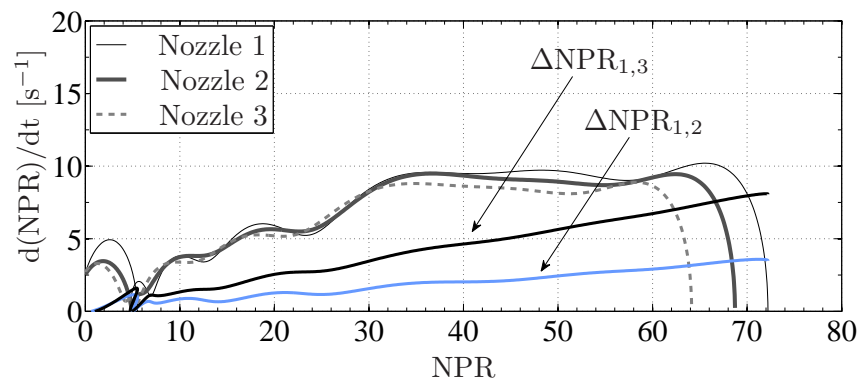

Figure 9: Nozzle pressure ratios recorded during stagger startup of the laboratory scale rocket cluster.

and a National Instruments cRIO system. These plenum pressure transducers were selected to operate over a range of 0-69 bar (0-1000 psig) with $0.05 \%$ of full-scale accuracy. Likewise barometric pressure was measured using a $660-813 \mathrm{mmHg}(26-32 \mathrm{inHg})$ with $0.05 \%$ full-scale accuracy. During testing, the atmospheric pressure inside the anechoic chambers drops because of the large amount of air that the rocket plumes entrain. Thus, all NPR values are based on the pressure measured inside the anechoic chamber with the sensing end of the port located 30 or so diameters from the rocket cluster (at the floor of the anechoic chamber). As was done for the full-scale data, $\Delta \mathrm{NPR}_{i, j}$ is computed and is shown to exhibit nearly linear growths over all NPRs. Thus, from Fig. 9 each nozzle plenum is shown to experience a pressure increase at the relatively flat rate of approximately 10 NPR per second between NPR 30 and 60. Both the stagger and without-stagger tests comprised three unique experiments (six total) in order to permit ensemble averaging in subsequent analysis.

Laboratory scale measurements utilized a single eighth-inch pressure field microphone (G.R.A.S. type 
46DD capsule) with matching preamplifier (G.R.A.S. type 26CB) and a static wall pressure sensing system (Scanivalve DSA3218 gas pressure scanners). The surface of the microphone's protective grid was mounted flush with the surface of the vehicle base located behind the nozzle cluster (see Fig. 7b). Microphone voltages were digitized at a rate of $100 \mathrm{kHz}$ using a NI-PXI-4472 board. The PXI-4472 board has built in low-pass filters that initiate roll-off at 0.84 of the nyquist frequency. As for the nozzle static wall pressure, three Scanivalve gas pressure scanners were used to provide insight into the shock foot pattern that forms on the interior surface of the nozzles at various instances during startup. A total of 36 ports were used (12 ports per nozzle) with each port distributed along the axial direction and with an axial spacing of $\Delta x / r^{*}=0.4$ spanning between $x / r^{*}=7.7$ and 12.1 ; nozzle exit planes are located at $x / r^{*}=12.5$. The location of these nozzle static wall pressure ports is shown in Fig. 8a with their white tubing being exposed in Fig. 7a.

\section{B. Analysis of Laboratory Data}

Contour plots of the static wall pressure (normalized by the ambient pressure in the chamber) are shown in Fig. 10 for all three nozzles, without and with stagger. FSS $\rightarrow$ RSS transition is shown to occur consistently around NPR 22 for all nozzles. A discussion of these contour patterns as they relate to FSS and RSS flow states is provided by Baars and Tinney. ${ }^{23}$ The NPR for each of these contour plots is calculated from each of their respective plenum pressures and with the sensing location of the barometric pressure transducer being at the floor of the anechoic chamber. Thus, the true NPR values (in close vicinity to the nozzle cluster) are slightly larger due to a decrease in local ambient pressure near the nozzle exit caused by the ejector effect of neighboring nozzles. The end-effects-regime is characterized by the intermittent opening of the last trapped annular separation bubble to the ambient which is shown to occur consistently around NPR $37 .{ }^{6,8}$ This was also verified by an audible tone that could be heard in the facility control room at this NPR. The repeatability of the shock foot pattern for each nozzle during the stagger case suggests that the flow and shock patterns are unaffected by the behavior of neighboring nozzles.

Where the microphone data is concerned, wavelet power spectra (WPS) are shown in Fig. 11 using the Morlet wavelet transform and the pressure ratio corresponding to nozzle 1. Only the region inside the cone of influence is displayed here and are generated by overlapping signal partitions of $N^{14}$ samples. These spectrograms are rich with information and demonstrate the complexity of the sound field produced during various operating states of these laboratory scale TOP nozzles. For the without-stagger tests, the end-effects regime acoustic signature appears as the dark vertical band between approximately $100 \mathrm{~Hz}$ and $3000 \mathrm{~Hz}$, and between NPR 37 and 39. The effect of stagger is revealed by the formation of additional dark bands now centered on NPR 38, 40, and 42, in Fig. 11b. Global wavelet power spectra are then generated by performing a window average over the WPS during instances along the NPR curve when the end-effects-regime tones appear. The results are displayed in Fig. 12 and reveal a $4 \mathrm{~dB}$ to $5 \mathrm{~dB}$ drop in amplitude at the most energetic frequencies when the end-effects-regime events do not overlap (i.e. are staggered). Two unique tones are more readily apparent and similar in appearance to the full-scale nozzles' GWPS shown in Fig. 6.

While the full-scale system encompasses a jet deflector, flame trench and water sound suppression system, the laboratory scale rocket nozzles were allowed to exhaust without any interruption in their flow path. Thus, additional sources of noise are present in the WPS of Fig. 11, which are not observed in the full-scale data. For example, broadband shock associated noise ${ }^{25-29}$ appears at both low NPRs (between NPR 4 and 16) and high NPRs (between NPR 35 and 70) while transonic resonance tones ${ }^{30}$ appear at low NPRs only and screech tones $^{31,32}$ at high NPRs only. A further discussion of these commonly known sources of jet and rocket noise, as they relate to the nozzles being tested here, are discussed in further detail by Canchero ${ }^{33}$ and Donald et al. ${ }^{10}$ These additional noise sources are not present in the wavelet power spectra of the full-scale data (Fig. 5a) which might be attributed to masking from either the launch platform or water suppression system (neither of these were simulated in the laboratory scale study). Therefore, a notch filter is applied to the laboratory scale acoustic pressure data between $100 \mathrm{~Hz}$ and $3 \mathrm{kHz}$ in order to remove any sources of noise not associated with the end-effects-regime. The effect of this filter on the raw acoustic pressure waveform is shown in Fig. 13a for a without stagger startup and reveals a signature more closely aligned with the full-scale data in Fig. 3a. The filter range is striaghtforward as most of the sound produced by broadband shock noise, transonic resonance and screech are shown to reside at much higher frequencies than the sound produced by the end-effects regime event.

Having analyzed the spectral characteristics of the acoustic waveforms, the next step is to inspect the scalar statistical metrics, as was done with the full-scale data. For this, both the original and filtered waveforms are scrutinized to gauge the effect of the notch filter on these metrics. In Fig. 13b, and 13c 


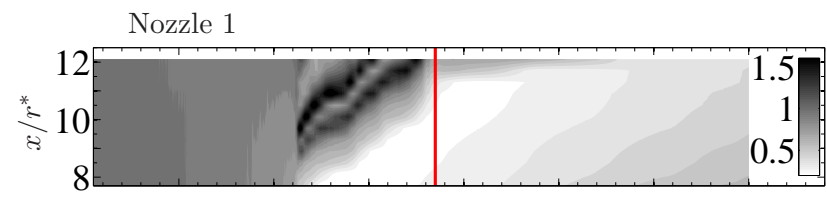

Nozzle 2

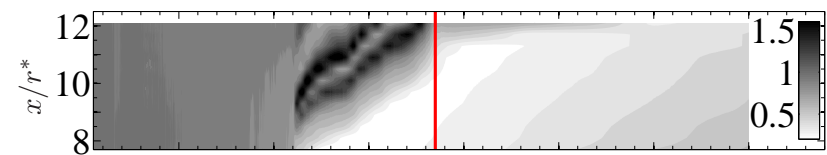

Nozzle 3

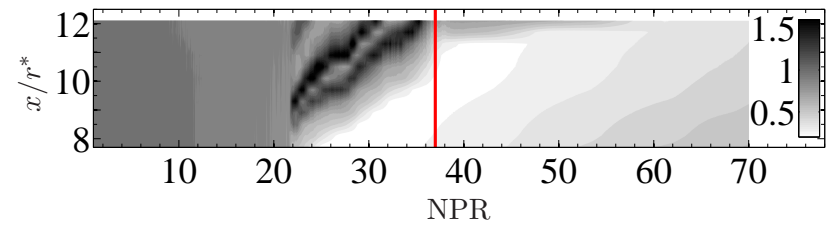

(a)

Nozzle 1

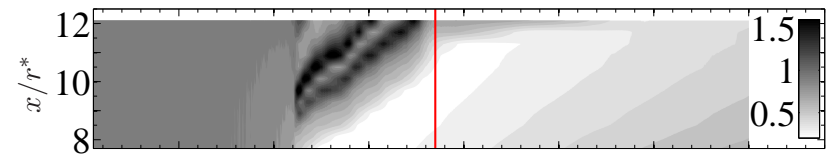

Nozzle 2

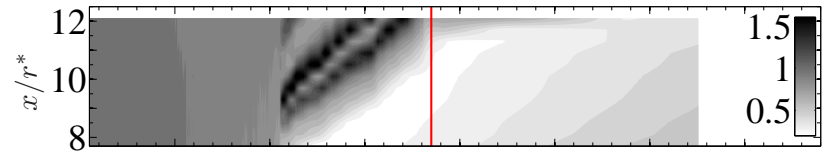

Nozzle 3

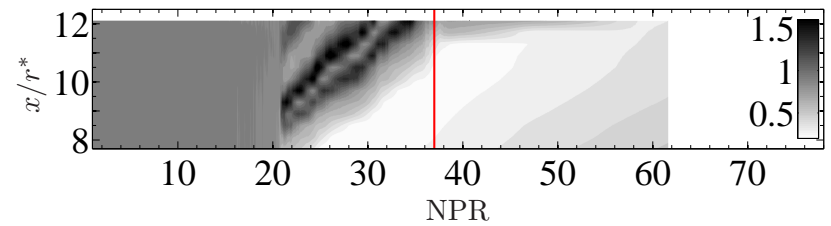

(b)

Figure 10: Normalized static wall pressure (a) without stagger and (b) with stagger. Vertical lines identify the location of NPR 37.

are the filtered time-series associated with the without-stagger and stagger tests (three tests per condition). Unlike the full-scale data, the laboratory scale microphone signals manifest good repeatability. The overall sound pressure level is then shown in Fig 14a and 14b using the acoustic pressure and its time derivative, respectively. OASPL is computed by window averaging the data with a window width that spans no more than two wavelengths of the high-pass filtered frequency $(100 \mathrm{~Hz})$. Both forms of the signal $(p(t)$ and $\dot{p}(t))$ display similar trends as was observed with the full-scale data in Fig. 4a. The effect of stagger is shown to reduce the OASPL amplitude of the filtered data by as much as $3 \mathrm{~dB}$. Three distinct peaks are observed in the staggered data and provide confidence in the window width selected for the averaging process.

As for skewness and kurtosis, these metrics are shown in Fig. 15 and are displayed in similar fashion as the OASPL. Starting with the pressure signal $p(t)$ in Fig. 15a, only the unfiltered waveforms exhibit elevated activity, but at instances along the NPR curve other than NPR 37. Thus, elevated skewness levels in the unfiltered pressure signal are attributed to either broadband shock associated noise or turbulence mixing noise, which are unrelated to the end-effects-regime event. Where the skewness of the pressure time derivative is concerned, Fig 15b conveys a different picture as the filtered data displays a single peak for the without-stagger test followed by three distinct peaks for the stagger test at NPR 37. Similar trends are observed in Fig. 15c and 15d for the kurtosis metric. As $S(\dot{p})$ is an indicator of the impulsiveness of 


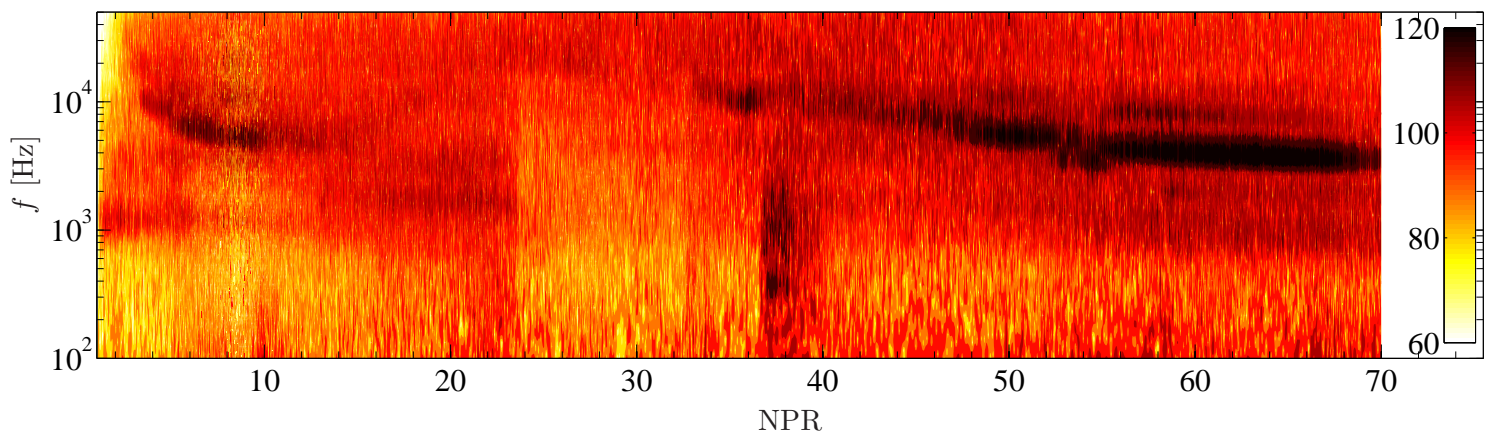

(a)

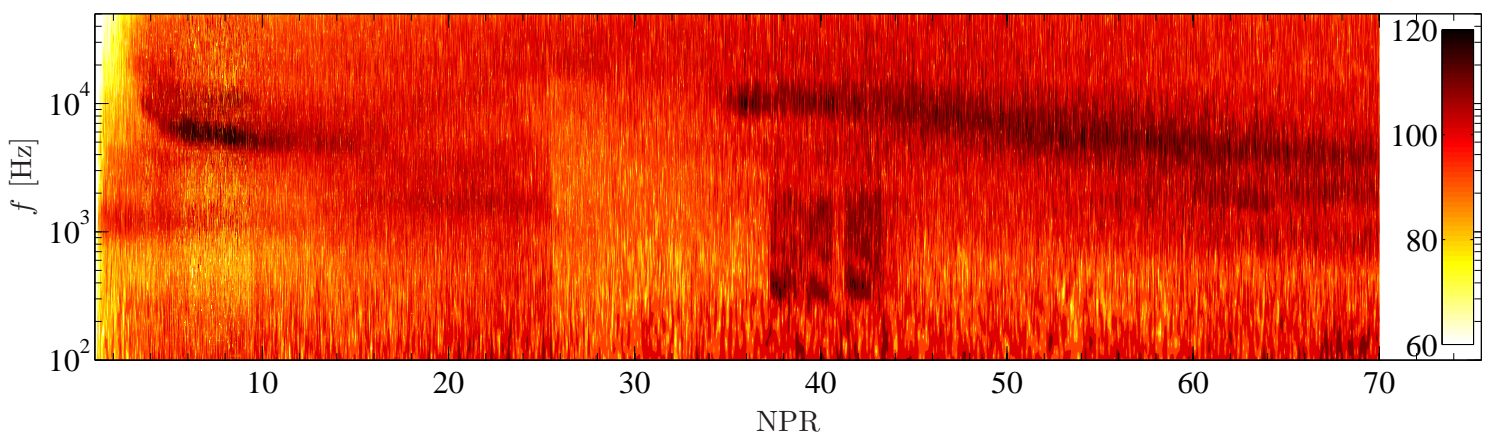

(b)

Figure 11: Morlet wavelet power spectra of the acoustic pressure during startup of the three-nozzle cluster plotted in $[\mathrm{dB}]$, (ref: $20 \mu \mathrm{Pa} / \sqrt{\mathrm{Hz}})$, following $10 \log _{10}(E(f, t) /$ ref $)$. One test (a) without stagger and (b) with stagger.

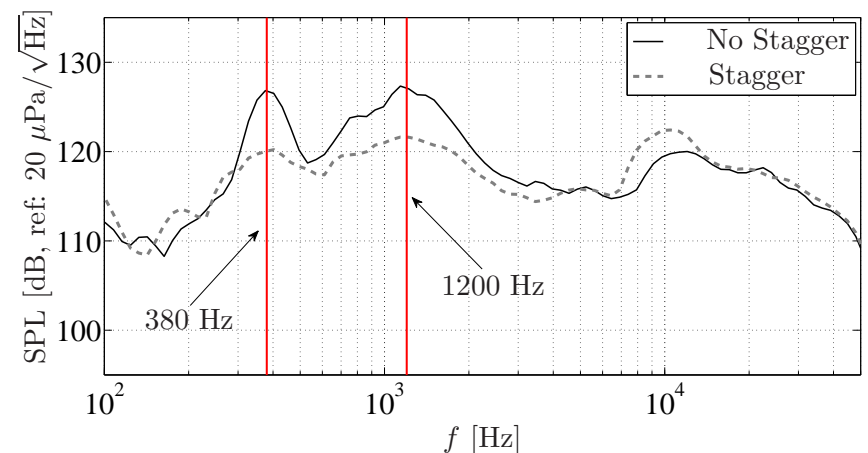

Figure 12: Global wavelet power spectra generated by averaging the wavelet power spectra in Fig. 11 between NPR 37 and NPR 38 for three without-stagger tests, and between NPR 37 and 40 for the three with-stagger tests.

the waveform, then it is shown here how staggering the nozzles does nothing in the way of removing this feature from the waveform. Thus, the acoustic waves that impact the base of the vehicle and surrounding structure are characterized by fast compressions followed by gradual expansions of the sound waves. Albeit, the OASPL levels are lower with the stagger tests, and so the amplitudes of the compressive wavefronts are not as violent. The elevated Kurtosis levels in the laboratory scale data are also observed in the full-scale analysis and demonstrate that these end-effects-regime loads are intermittent. 


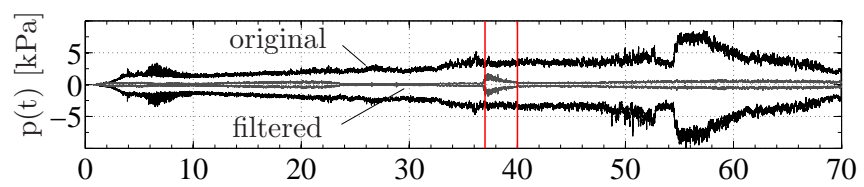

(a)

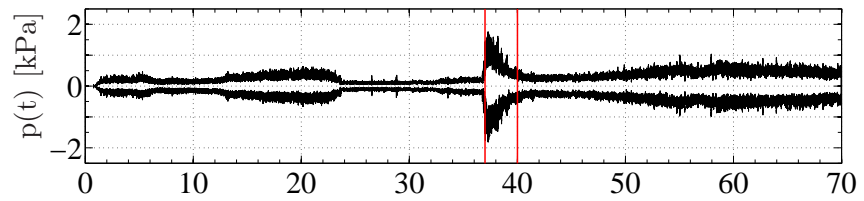

(b)

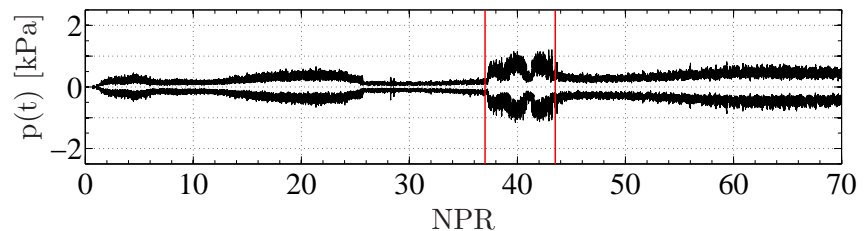

(c)

Figure 13: (a) Maximum and minimum envelops of a sample raw pressure waveform acquired during a without-stagger startup (lab scale). Maximum and minimum envelops for (b) three without-stagger tests and (c) three stagger tests.

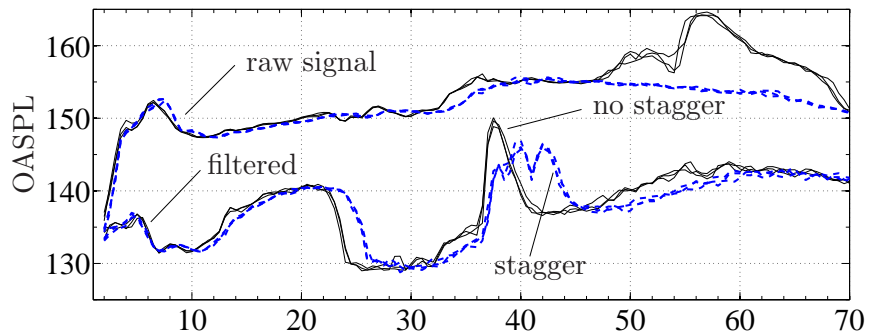

(a)

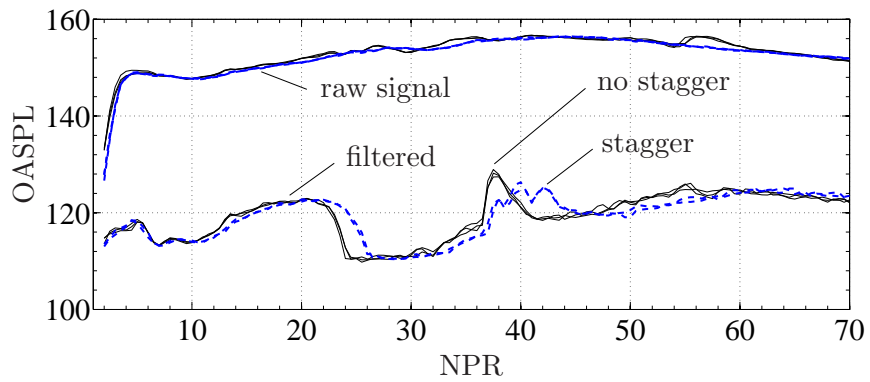

(b)

Figure 14: OASPL (dB, re: $20 \mu \mathrm{Pa} \sqrt{\mathrm{Hz}})$ of the (a) acoustic pressure waveform and (b) its time derivative from three separate laboratory scale tests.

\section{Inspection of the End-Effects-Regime}

At this point, the discussion and analysis has focused on the effect that stagger startup has on the vibroacoustic loads that form at the base of a vehicle geometry with a particular emphasis on the end-effects

$$
12 \text { of } 16
$$




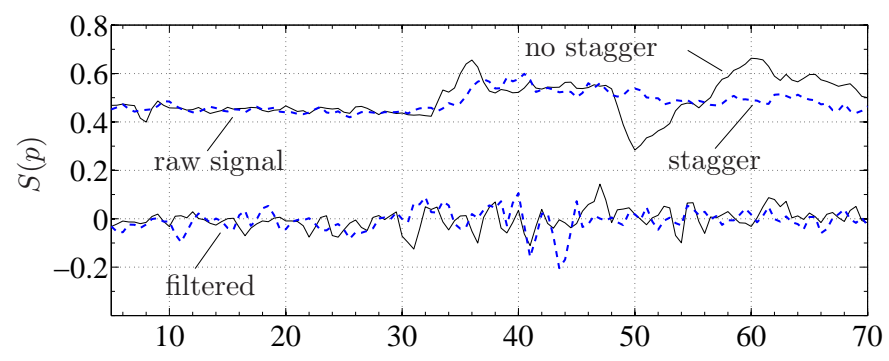

(a)

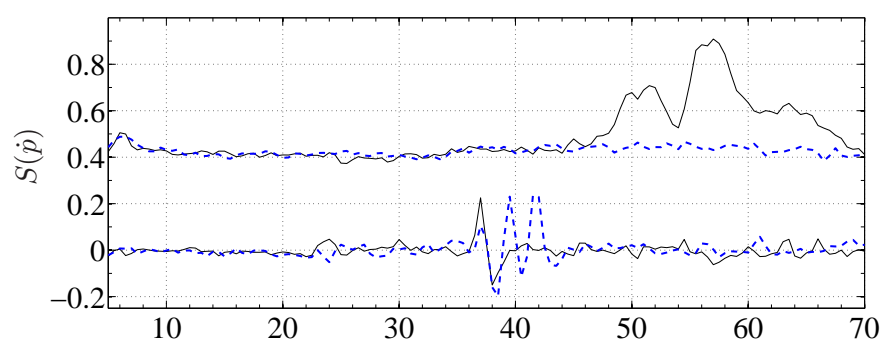

(b)

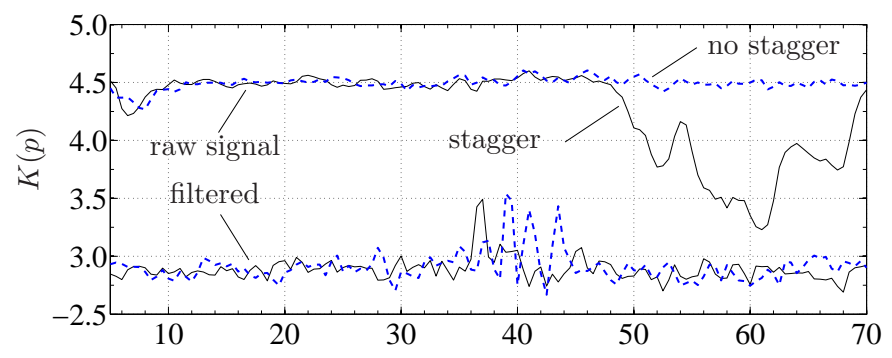

(c)

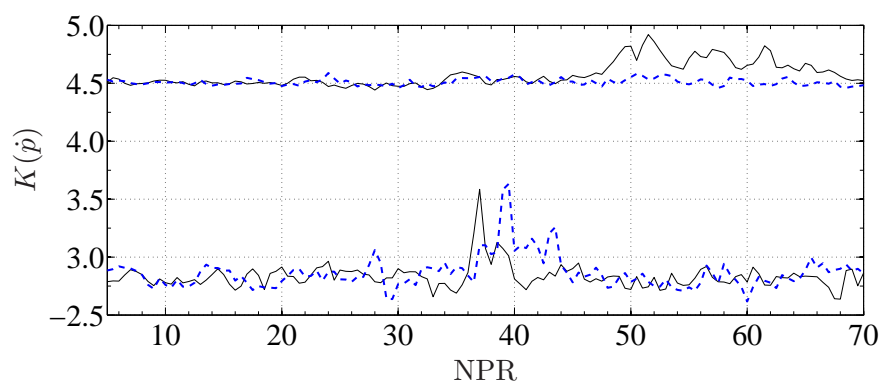

(d)

Figure 15: (a) Skewness of the pressure signal $p(t)$ averaged over the three laboratory tests. The raw signal is shifted upward by 0.4 relative to the filtered signal. (b) Skewness of the pressure time derivative $\dot{p}(t)$ following the same procedure in (a). (c) Kurtosis of the pressure signal $p(t)$ and (d) its time derivative $\dot{p}(t)$ averaged over the three laboratory tests. The raw signal is shifted upward by 1.5 relative to the filtered signal.

regime. We have only postulated that these vibroacoustic loads are caused by EER, but have yet to prove this quantitatively. To address this concern, we will turn to an analysis of the dynamic wall pressure during steady operations (NPR 37) of the three nozzle configuration without stagger. For this three nozzle cluster, 
two of the three nozzles are each outfitted with a single Kulite model XT-140-100A dynamic wall pressure transducer. These transducers comprise a dynamic range of $100 \mathrm{psia}$ ( $\pm 1 \%$ full-scale) and were installed so that their protective B-type screens, with $2.62 \mathrm{~mm}$ outside diameter, were flush with the interior surface of the nozzle at $x / r^{*}=11.7$. Fig. 8a identifies the location of this Kulite port and is specifically chosen to capture the unsteady wall pressure associated with the intermittent opening of the last annular separation bubble with the atmosphere. Signal conditioning and digitization was provided by a NI-PXIe-4331 board embedded in a PXI-1073 chassis while the sampling rate was set to $40 \mathrm{kHz}$.

A sample set of Kulite data from one of the transducers is shown in Fig. 16. Here, the NPR increases gradually to NPR 50, after which it is brought down where EER occurs. The pressure ratio is then held steady for an extended period of time (between $t=18 \mathrm{~s}$ and $28 \mathrm{~s}$ ) thereby allowing spectral analysis to be performed on the dynamic wall pressure during EER. The high pressure humps seen at $t=9 \mathrm{~s}$ and $t=15 \mathrm{~s}$ in Fig. 16 are the signatures corresponding to shocks in the annular RSS flow passing over the Kulite as NPR was increased. ${ }^{23,34}$ At $t=18 \mathrm{~s}$, the flow enters a long period of continuous EER where the annular RSS flow structure moves up- and downstream rapidly. The wall pressure alternates between 0.4 and 1.8 atmospheres as separation bubbles and shocks in the annular RSS flow pass back and forth over the transducer. Focusing on the ERR between $t=18$ and $28 \mathrm{~s}$ in Fig. 16, it can be seen that the pressure fluctuations vary both in magnitude and frequency. This variation results from the changes of shock strength and in distance the RSS flow structure moves within the nozzle in response to the variations in NPR.

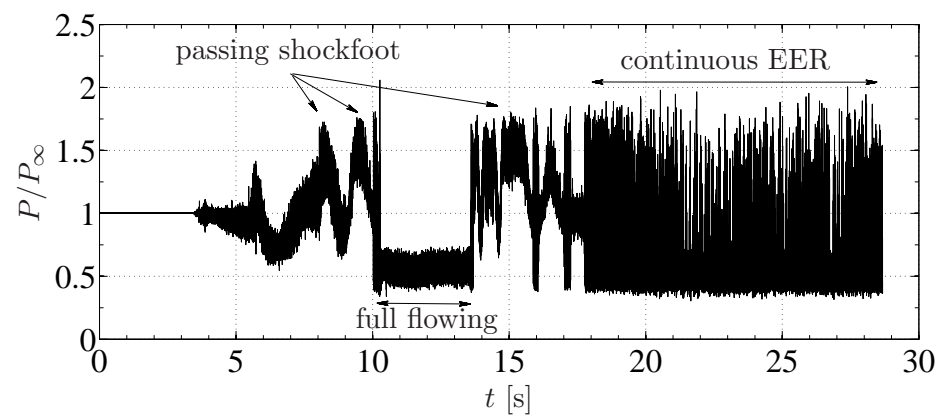

Figure 16: Normalized dynamic wall pressure reading during startup of the three-nozzle cluster to full flowing conditions, followed by a steady operation at NPR 37 .

Focusing our attention on the EER event during the window of time between $t=18$ and $28 \mathrm{~s}$ in Fig. 16, the spectral density is computed and compared in Fig. 17 with the 1/8 inch microphone spectra acquired at the base of the vehicle. The frequency resolution for the Kulites and acoustic microphone data are $\delta f=4.9$ and 6.1 , and are based on block sizes of $2^{13}$ and $2^{14}$, respectively. One can see that the peak frequency in the wall pressure spectra aligns with the peak frequency in the acoustic spectra, thus confirming the source of the vibroacoustic loads during EER. It is postulated that the slight shift is attributed to nonlinear acoustic distortion of the acoustic waves that become amplified through coalescence with neighboring sources (from adjacent nozzles) and thus travel at faster speeds. ${ }^{35}$ This is confirmed by the elevated skewness of the pressure time derivative measured at the base of the vehicle at NPR 37 as shown in Fig. 15b.

\section{Summary \& Conclusions}

This study focuses on quantifying the vibroacoustic loads that form at the base of a space launch vehicle during startup of clustered rocket nozzles. The configuration comprises three nozzles and the effect that stagger startup has on these vibroacoustic loads. Both full-scale and laboratory scale nozzle hardware are analyzed with an emphasis on the end-effects-regime. This end-effects-regime is categorized by an onset of relatively low frequency energy driven by intermittent buffeting between RSS flow and a partialFSS flow at the nozzle lip. The full-scale data is acquired with the presence of a launch pad with tower, flame trench and water suppression system, and with nozzles comprising compliant walls. Laboratory scale measurements, on the other hand, employ rigid walls and are studied with an exhaust plume that flows without obstructions. Analysis of the acoustic pressure at the base of the full-scale vehicle reveals a significant increase in vibroacoustic energy during the end-effects-regime. A time-frequency analysis of this data exposes the peak frequencies associated with this elevated acoustic load, while higher order metrics, (skewness and 


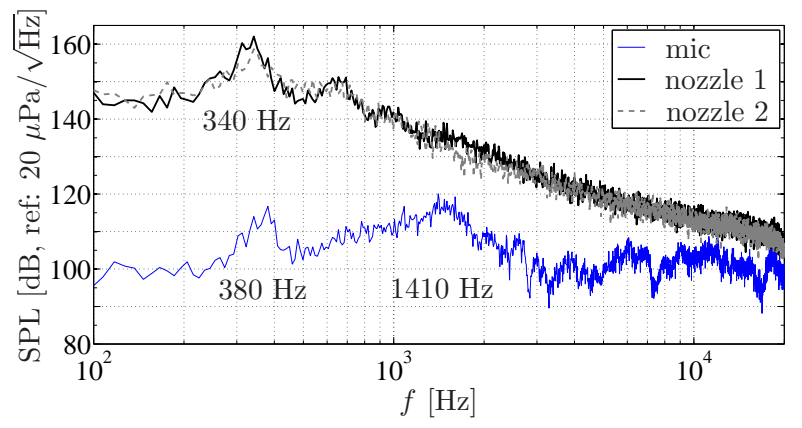

Figure 17: Power spectral densities of the nozzle dynamic wall pressure and acoustic pressure at the base of the three nozzle cluster.

kurtosis of the pressure and its time derivative) quantify distortions in the acoustic signal.

For the laboratory scale measurements, additional sources of noise are observed and are attributed to high frequency broadband shock associated noise, screech and transonic resonance. Upon employing a notch filter, these additional sources of noise are removed and reveal the same bursting like events observed in the full-scale study. In doing so, a more representative analysis is conducted to see the effect that engine stagger has on vibroacoustic loads that form during startup.

The stagger startups are achieved in the laboratory tests by inserting orifice plates (comprising various hole patterns) upstream of the nozzle throat. In doing so, both stagger and without-stagger startups are explored. Upon analyzing the acoustic pressure at the base of the vehicle geometry, the stagger startups result in a $3 \mathrm{~dB}$ decrease in the OASPL as well as a $5 \mathrm{~dB}$ decrease in the peak frequencies. During EER, the acoustic waveforms, as sensed at the base of the vehicle, encompass sawtoothlike waveforms as revealed by an analysis of the skewness and kurtosis of both the pressure and its time derivative. The dynamic wall pressure near the nozzle lip was also investigated, and showed a correlation between pressure fluctuations measured at the nozzle lip and the spectral content of the acoustic data acquired at the base of the vehicle geometry.

\section{Acknowledgments}

Funding for this work was graciously provided by the NASA Engineering and Safety Center at NASA Langley.

\section{References}

\section{References}

\footnotetext{
${ }^{1}$ Rao, G. V. R., "Exhaust nozzle contour for optimum thrust," Jet Propulsion, Vol. 28, No. 6, 1958, pp. 377-382.

${ }^{2}$ Baars, W.J., Tinney, C.E., Ruf, J.H., Brown, A.M., and McDaniels, D.M., "Wall pressure unsteadiness and side loads in overexpanded rocket nozzles," AIAA Journal, Vol. 50, No. 1, Jan. 2012, pp. 61-73.

${ }^{3}$ Frey, M., and Hagemann, G., "Restricted shock separation in rocket nozzles," Journal of Propulsion and Power, Vol. 16, No. 3, May 2000, pp. 478-484.

${ }^{4}$ Verma, S. B., and Haidn, O. "Study of Restricted Shock Separation Phenomena in a Thrust Optimized Parabolic Nozzle," Journal of Propulsion and Power Vol. 25, No. 5, 2009, pp. 1046-1057.

${ }^{5}$ Martelli, E., Nasuti, F., and Onofri, M., "Numerical calculation of FSS/RSS transition in highly overexpanded rocket nozzle flows." Shock Waves Vol. 20, 2010, pp.139-146.

${ }^{6}$ Nave, L. H., and Coffey, G. H., "Sea level side loads in high-area-ratio rocket engines," AIAA/SAE 9th Propulsion Conference, AIAA Paper 1973-1284, Nov. 1973.

${ }^{7}$ Frey, M., and Hagemann, G., "Flow separation and side-loads in rocket nozzles," 35th AIAA/ASME/SAE/ASEE Joint Propulsion Conference and Exhibit, AIAA Paper 1999-2815, July 1999.

${ }^{8}$ Nguyen, A. T., Deniau, H., Girard, S., and Alziary de Roquefort, T., "Unsteadiness of flow separation and end-effects regime in a thrust-optimized contour rocket nozzle," Flow, Turbulence and Combustion, Vol. 71, Nos. 1-4, 2003 , pp. 161-181.

${ }^{9}$ Wang, T.-S., Lin, J., Ruf, J., and Guidos, M. 'Transient three-dimensional side-load analysis of out-of-round film-cooled nozzles," Journal of Propulsion and Power Vol. 27, No. 4, 2011, pp. 899-907.
} 
${ }^{10}$ Donald, B.W., Baars, W. J., Tinney, C. E., and Ruf, J. H. "Sound produced by large area-ratio nozzles during fixed and transient operations," AIAA Journal, Vol. 52, No. 7, 2014, pp. 1474-1485.

${ }^{11}$ Mayes, W. H., Lanford, W. E., and Hubbard, H. H. "Near-field and far-field noise surveys of solid-fuel rocket engines for a range of nozzle exit pressures," NASA Technical Note Vol. 21, August 1959.

${ }^{12}$ Wilhold, G. A., Guest, S. H., and Jones, J. H., "A technique for predicting far-field acoustic environments due to a moving rocket sound source," NASA TN D-1832, Aug. 1963, pp. 1-39.

${ }^{13}$ Guest, S.H., "Acoustic efficiency trends for high thrust boosters," NASA TN D-1999, July 1964, pp. 1-10.

${ }^{14}$ Eldred, K. M. "Acoustic loads generated by the propulsion system," NASA SP-8072, June 1971, pp. 1-49.

${ }^{15}$ Sutherland, L. C., "Progress and problems in rocket noise prediction for ground facilities," 15th Aeroacoustics Conference, AIAA Paper 1993-4383, Oct. 1993.

${ }^{16}$ McInerny, S. A., "Launch vehicle acoustics part 1: Overall levels and spectral characterization," Journal of Aircraft, Vol. 33, No. 3, 1996, pp. 511-517.

${ }^{17}$ Varnier, J., "Experimental study and simulation of rocket engine freejet noise," AIAA Journal, Vol. 39, No. 10, Oct. 2001, pp. 1851-1859.

${ }^{18}$ Panda, J., and Mosher, R., "Use of a microphone phased array to determine noise sources in rocket plumes," 49th Aerospace Sciences Meeting and Exhibit, AIAA Paper 2011-974, Jan. 2011.

${ }^{19}$ Bendat, J.S. and Piersol, A.G. "Random Data Analysis and Measurement Procedures," Fourth Edition, Wiley Series in Probability and Statistics, Wiley, 2010, Ch. 5.

${ }^{20}$ McInerny, S. A., "Launch vehicle acoustics part 2: Statistics of the time domain data," Journal of Aircraft, Vol. 33, No. 3, 1996, pp. 518-523.

${ }^{21}$ Farge, M., "Wavelet transforms and their application to turbulence," Annual Review of Fluid Mechanics, Vol. 24, Jan. 1992, pp. 395-458

22 Addison, P. S., "The illustrated wavelet transform handbook," Taylor \& Francis Group, New York, 2002.

${ }^{23}$ Baars, W. J., and Tinney, C. E., "Transient wall pressure in an overexpanded and large area-ratio nozzle," Experiments in Fluids, Vol. 54:1468, Feb. 2013, pp. 1-17.

${ }^{24}$ Ruf, J. H., McDaniels, D. M., and Brown, A. M. "Details of Side Load Test Data and Analysis for a Truncated Ideal Contour Nozzle and a Parabolic Contour Nozzle," 46th AIAA/ASME/SAE/ASEE Joint Propulsion Conference and Exhibit, AIAA Paper 2010-6813, July 2010.

${ }^{25}$ Ribner, H. S. "Acoustic flux from shock-turbulence interaction," Journal of Fluid Mechanics, Vol. 35, No. 2, 1969, pp. 299-310.

${ }^{26}$ Harper-Bourne, M., and Fisher, M. J. "The noise from shock waves in supersonic jets," Proc. AGARD Conf. on Noise Mech. AGARD-CP-131-11, 1973, pp. 1-13.

${ }^{27}$ Norum, T. D., and Seiner, J. M. "Broadband shock noise from supersonic jets," AIAA Journal, Vol. 20, No. 1, 1982, pp. 68-73.

${ }^{28}$ Tam, C. K. W., and Tanna, H. K. "Shock associated noise of supersonic jets from convergent-divergent nozzles," Journal of Sound and Vibration, Vol. 81, No. 3, 1982, pp. 337-358.

${ }^{29}$ Pao, S. P., and Seiner, J. M. "Shock-associated noise in supersonic jets," AIAA Journal, Vol. 21, No. 5, 1983, pp. 687-693.

${ }^{30}$ Zaman, K. B. M. Q., Dahl, M. D., Bencic, T. J., and Loh, C.Y., "Investigation of a 'transonic resonance' with convergentdivergent nozzles," Journal of Fluid Mechanics, Vol. 463, July 2002, pp. 313-343.

${ }^{31}$ Raman, G., "Advances in understanding supersonic jet screech: review and perspective," Progress in Aerospace Sciences, Vol. 34, Nos. 1-2, Jan. 1998, pp. 45-106.

${ }^{32}$ Norum, T.D., "Screech suppression in supersonic jets," AIAA Journal, Vol. 21, No. 2, Feb. 1983, pp. 235-240.

${ }^{33}$ Canchero, A., "Retroreflective shadowgraph of clustered rocket nozzles," MS thesis, The University of Texas at Austin, Austin, Texas, USA.

${ }^{34}$ Baars, W. J., Ruf, J.H., and Tinney, C. E., "Non-stationary shock motion unsteadiness in an axisymmetric geometry with pressure gradient," Experiments in Fluids, Vol. 56:92, 2015, pp. 1-18.

${ }^{35}$ Fiévet, R., Tinney, C. E., Baars, W. J., and Hamilton, M. F. "Coalescence in the sound field of a laboratory-scale supersonic jet," AIAA Journal, DOI 10.2514/1.J054252, 2015, pp. 1-12. 